\title{
A CASE STUDY FOR A NEW APPROACH OF A CONSTANT PRESSURE PERFUSED EX-VIVO MODEL OF THE EQUINE LARYNX
}

\author{
S. Otto, V. Tast, J. K. Michler, Ch. K. W. Mülling \\ Institute of Veterinary Anatomy, University of Leipzig, Germany \\ sven.otto@vetmed.uni-leipzig.de
}

\begin{abstract}
This paper describes an improved setup for the perfusion of an isolated equine larynx under constant pressure conditions. Aim is to provide a reliable and standardized model for measurements of the threedimensional electrical field distribution of implanted electrodes into the laryngeal muscles for the future treatment of hemiplegia laryngis in horses.

The basic findings which are reported here provide an overview on the technical devices and show data of an exemplary case study.

Measurements were first performed to determine perfusion flow. Through increasing and decreasing the perfusion pressure and application of adrenalin it could be shown that the tissue reacted in its anticipated physiological function by adjusting the perfusion flow.
\end{abstract}

Keywords: Horse, hemiplegia laryngis, functional electric stimulation (FES), ex-vivo model, perfusion

\section{Introduction}

Hemiplegia laryngis, in horses also referred to as whistling or roaring, is caused by a dysfunction of the recurrent laryngeal nerve. The reported prevalence has an extremely wide range from $1.2-42 \%$ in different horse breeds [1]. Different surgical methods for the treatment of this disorder have been described. Laryngeal hemiplegia causes a relative upper airway obstruction because the recurrent laryngeal nerve shows a loss in its function to innervate the dorsal cricoarytenoid muscle (CAD). An electrical stimulation of the CAD leads to an opening of the upper airways [1].

One therapy option is called functional electric stimulation (FES). FES for this application was first described in 1977 [2]. In order to improve the outcome of this method, one approach is the measurement of the $3 \mathrm{D}$ distribution of the electric field around implanted stimulation electrodes [3].

The objective of this case study was to improve the exvivo model for the equine larynx used by Martini et al. [3] and to create a model which is intended to closely mimic the physiological in-vivo situation. Specific aims of our improved model were:

-reduction of swelling due to tissue edema -examination of the myogenic autoregulation -monitoring of the vessels' physiological response through the application of adrenalin

The methodology for the perfusion in our ex-vivo model of the equine isolated larynx is outlined in this report.

\section{Methods}

One horse was euthanized in consent with the national council's guidelines of animal care (protocol number: T66/13).

Reportedly, the horse had no hemiplegia laryngis and there were no signs of hemiplegia laryngis during our clinical examination. Via intravenous (i.v.) application of Xylazine $(1 \mathrm{mg} / \mathrm{kg})$ the horse was sedated and general anaesthesia was induced by i.v. application of Diazepam $(0.08 \mathrm{mg} / \mathrm{kg})$ and Ketamine $(2.2 \mathrm{mg} / \mathrm{kg})$. Finally the horse was euthanized with Pentobarbital $(80 \mathrm{mg} / \mathrm{kg})$.

The larynx was separated and both cranial thyroid arteries were catheterised for flushing the organ with a modified Tyrode's solution at $4^{\circ} \mathrm{C}$. Subsequently, the larynx was immersed in the aforementioned solution. It was then transferred to the laboratory within half an hour.

Fig. 1 gives an overview of the experimental setup. The larynx was placed in an acrylic glass tub filled with prewarmed perfusion solution $\left(33^{\circ} \mathrm{C}\right)$ and was fixed at the bottom and the sides with elastomeric impression material (Eurosil Max 2, HENRY SCHEIN®, Langen). The above mentioned arterial vessels were connected to a closed constant pressure perfusion system. The perfusion solution was gassed with Carbogen $\left(95 \% \mathrm{O}_{2}, 5 \% \mathrm{CO}_{2}\right.$, LINDE GAS, Unterschleißheim). The larynx was perfused with warmed perfusion solution $\left(37^{\circ} \mathrm{C}\right)$ and constant perfusion pressure of $9.81 \mathrm{kPa}$ for 2 hours.

Subsequently, perfusion flow was determined based on the difference between the influx and overflow $(\Delta \mathrm{Q})$ of the medium tank (Tab. 1). In order to achieve a constant influx rate a pump was used (Masterflex $\subset$ Model 170100A, RADNOTI LLC, CA, USA). The overflow was measured by using a standardized glass cylinder. The perfusion pressure was increased to $10.89 \mathrm{kPa}$ and the perfusion flow was measured again (Tab. 2). Afterwards, perfusion pressure was reset to the onset and measurement of perfusion flow was repeated (Tab. 3). Finally, 0.5 mg Adrenaline was injected into each cranial thyroid artery and perfusion flow was measured (Tab. 4).

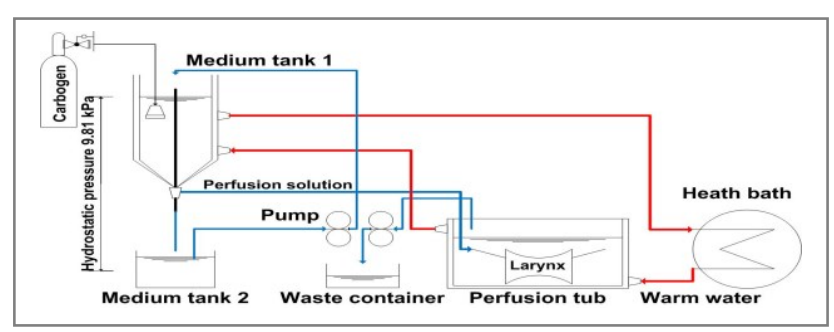

Figure 1: Diagram of the experimental setup 


\section{Results}

The baseline flow after 2 hours of perfusion is shown in Tab. 1.

Table 1: Baseline perfusion flow at $9.81 \mathrm{kPa}$ perfusion pressure

\begin{tabular}{|l|ccccc|}
\hline time (min) & $\mathbf{1}$ & $\mathbf{2}$ & $\mathbf{3}$ & $\mathbf{4}$ & $\mathbf{5}$ \\
\hline$\Delta \mathbf{Q}(\mathbf{m l} / \mathbf{m i n})$ & 30 & 28 & 30 & 30 & 26 \\
\hline $\begin{array}{l}\text { calculated } \\
\text { flow (ml/min) }\end{array}$ & 70 & 72 & 70 & 70 & 74 \\
\hline
\end{tabular}

Perfusion flow increased 2 minutes after the perfusion pressure was increased by $1.08 \mathrm{kPa}$ and then decreased to the baseline perfusion flow after 5 minutes as shown in Tab. 2 .

Table 2: Perfusion flow at $10.89 \mathrm{kPa}$ perfusion pressure

\begin{tabular}{|l|ccccc|}
\hline time (min) & $\mathbf{1}$ & $\mathbf{2}$ & $\mathbf{3}$ & $\mathbf{4}$ & $\mathbf{5}$ \\
\hline$\Delta \mathbf{Q}(\mathbf{m l} / \mathbf{m i n})$ & 28 & 22 & 22 & 24 & 26 \\
\hline $\begin{array}{l}\text { calculated } \\
\text { flow (ml/min) }\end{array}$ & 72 & 78 & 78 & 76 & 74 \\
\hline
\end{tabular}

Perfusion flow decreased in relation to the initial perfusion flow 2 minutes after the perfusion pressure was reset to $9.81 \mathrm{kPa}$ and then increased to the baseline perfusion flow (Tab. 3).

Table 3: Perfusion flow after perfusion pressure was reset to $9.81 \mathrm{kPa}$

\begin{tabular}{|l|ccccc|}
\hline time (min) & $\mathbf{1}$ & $\mathbf{2}$ & $\mathbf{3}$ & $\mathbf{4}$ & $\mathbf{5}$ \\
\hline$\Delta \mathbf{Q}(\mathbf{m l} / \mathbf{m i n})$ & 36 & 34 & 28 & 32 & 30 \\
\hline $\begin{array}{l}\text { calculated } \\
\text { flow (ml/min) }\end{array}$ & 64 & 66 & 72 & 68 & 70 \\
\hline
\end{tabular}

Finally the perfusion flow decreased markedly compared to all other measured perfusion flows after $0.5 \mathrm{mg}$ Adrenaline had been administered via each cranial thyroid artery (Tab. 4).

Table 4: Perfusion flow after injection of $0.5 \mathrm{mg}$ Adrenaline into each cranial thyroid artery

\begin{tabular}{|l|ccc|}
\hline time (min) & $\mathbf{1}$ & $\mathbf{2}$ & $\mathbf{3}$ \\
\hline$\Delta \mathbf{Q}(\mathbf{m l} / \mathbf{m i n})$ & 54 & 62 & 60 \\
\hline $\begin{array}{l}\text { calculated } \\
\text { flow (ml/min) }\end{array}$ & 46 & 38 & 40 \\
\hline
\end{tabular}

The larynx visually showed no significant signs of tissue swelling.

\section{Discussion}

In this experiment, we developed a new approach of a pressure constant perfused ex-vivo model of the equine larynx and provide preliminary data on flow and myogenic response. To our knowledge, no data regarding the physiological perfusion flow of the equine larynx have been published.
Ex-vivo organs can be perfused in a flow constant or pressure constant model [4], [5]. When using a constant flow model, the knowledge of the physiological perfusion flow of the used organ is important in order to avoid an excessive perfusion of the organ.

The myogenic response (Bayliss effect) is a special effect in smooth vascular cells that helps to sustain a constant capillary flow independent of changes in arterial blood pressure [6]. Adrenaline is a typical $\alpha 1$-adrenoceptor agonist that causes vasoconstriction which in term leads to an increase of resistance and decrease of flow in vessels (Hagen-Poiseuille's law). We could show that after 2 hours of perfusion in our model the tissue of the larynx was still able to react properly in its anticipated physiological function by adjusting the perfusion flow showing maintained myogenic autoregulation. We were also able to minimize the swelling effects described by Martini et al. [3].

Using a larger number of animals would lead to more stable results. Also the use of histological methods and to weigh the used organ before and after perfusion could show the degree of tissue swelling more accurately.

Our model very closely mimics the in-vivo situation. It provides a reliable platform for further studies on the three-dimensional distribution of the electrical field of multipolar intra-muscular FES stimulation electrodes.

\section{Acknowledgement}

This work was supported by a grant from Medical-el Elektromedizinische Geräte GmbH, A-6020 Innsbruck, Austria. We thank Professor Dhein from the Heart Center Leipzig for his helpful and valuable comments on our study design and the Surgical Large Animal Clinic (University of Leipzig) for their kind support.

\section{Bibliography}

[1] Ducharme, N. G., Cheetham, Jon, et. al.: Considerations for pacing of the cricoarytenoid dorsalis muscle by neuroprosthesis in horses, Equine Vet. J., vol. 42, pp. 534540, Sept. 2010

[2] Zealear , D. L., Dedo, H.H.: Control of paralysed axial muscles by electrical stimulation, Acta Otolaryngol., vol. 83(5-6). pp. 514-27, 1977

[3] Martini P., Cercone, M. et al.: Experimental electrical field distribution measurements in a perfused ex vivo model, Biomed Tech., vol.57, pp. 870-3, 2012

[4] Dhein, S.: „The Langendorff Heart” in Practical Methods in Cardiovascular Research (S. Dhein, F. W: Mohr, M. Delmar, eds.), ch. 2.1, pp. 155-172, Berlin, Heidelberg, New York: Springer, 2005

[5] Langendorff, O.: Untersuchungen am überlebenden Säugethierherzen, Pflügers Arch Ges Physiol, vol. 61, pp. 291-331, 1895

[6] Bayliss, W. M.: On the local reactions of the arterial wall to changes of internal pressure, J Physiol., vol. 28, pp.220-231, 1902 